\title{
Decline Curve Analysis: A Comparative Study of Proposed Models Using Improved Residual Functions
}

\author{
Paryani $\mathbf{M}^{*}$, Ahmadi $M$, Awoleke $\mathrm{O}$ and Hanks $\mathrm{C}$ \\ College of Engineering and Mines, The Society of Petroleum Engineers, University of Alaska, Fairbanks, USA
}

\begin{abstract}
The flow behavior in nano-darcy shales neighbored by high conductivity induced natural fractures violates the assumptions behind Arps' decline models that have been successfully used in conventional reservoirs for decades. Current decline curve analysis models such as Logistic Growth Analyses, Power Law Exponential and Duong's model attempt to overcome the limitations of Arps' model. This study compares the capability of these models to match the past production of hundred shale oil wells from the Eagle Ford and investigate how the choice of residual function affects the estimate of model parameters and subsequently the well life, pressure depletion and ultimate recovery. Using the proposed residual functions increased the tendency of deterministic models to have bounded estimates of reserves. Results regarding well performance, EUR, drainage area and pressure depletion are obtained quickly and show realistic distributions supported by production hindcasts and commercial reservoir simulators. Overall, the PLE and Arps' hyperbolic models predicted the lowest/pessimistic and highest/optimistic remaining life/reserves respectively. The newly proposed residual functions were thereafter used with the Arps' hyperbolic and LGA models. We found that the use of rate-time residual functions increased the likelihood of the value of hyperbolic exponent being less than 1 by $87.5 \%$. The proposed residual functions can be used to provide optimistic and conservative estimations of remaining reserves and remaining life using any of the above decline models for economic analysis. The key results provided by the modified DCA models help in long-term planning of operations necessary for optimal well completions and field development, accomplished in a fraction of the time currently required by other complex software and workflows.
\end{abstract}

Keywords: Decline curve analysis; Production forecast; Unconventional reservoir

Abbreviations: $\boldsymbol{q}$ : Production rate, volume/time; $t$ : Time; $b$ : Decline exponent $0 \leq b \leq 1 ; q(t)$ : Production rate at time $\mathrm{t}$, volume/time; $q_{i}$ : Initial production rate, volume/time; $D_{i}$ : Initial decline constant, $1 /$ time; $Q(t)$ : Cumulative production, volume; $K$ : Carrying capacity, STB; $a^{n}$ : Constant of $t^{n}$, time; $n$ : Exponential parameter; $a$ : Intercept constant, $1 /$ time; $m$ : Slope; $q_{1}$ : Oil rate at day $1 ; q_{\alpha}$ : Oil rate at infinite time; $t(a, m)$ : Time function; $\hat{D}_{i}:$ Rate at $\mathrm{t}=0$, volume/time; $D_{1}$ : Decline constant after at time $=1,1 /$ time; $D_{a}$ : Decline constant at infinite time, 1/time; $\hat{D}_{i}$ : Decline constant $=\mathrm{D}_{1} / n, 1 /$ time; $n^{\prime}$ : Time exponent; $q(t)$ : Production rate of month $i, \mathrm{STB} /$ day; $t$ : Number of days in month $i$, days; $x$ : The month number when rate is $2 \mathrm{STB} /$ day

\section{Introduction}

Decline curve analysis (DCA) is a technique where production data from a well or reservoir is used to predict the well/reservoir future production. Two important goals of DCA are to estimate the remaining reserves and the remaining life down to a specified economic limit, both of which are important for determining the economic viability of a shale resource play. The behavior of fluid flow in extremely tight porous media neighbored by high conductivity induced and/or natural fractures creates challenges in forecasting the performance of shale oil wells/reservoirs. Transient and fracture-dominated flow regimes demand new well performance evaluation techniques. Evaluating Arps' model assumptions for decline curve analysis highlights its limitations when applied to shale reservoirs and the need for better models for these unconventional reservoirs.

Wells producing from shale reservoirs are all hydraulically fractured. Production commences with $100 \%$ water and the water cut decreases over the life of the well. It takes few weeks to few months for oil/gas production rate to reach its maximum followed by a steep decline in production. This is partially due to production being dominated by the stimulated reservoir volume (SRV) with little contribution from the reservoir matrix [1]. This and other complexities of shale reservoirs cause the Arps' model to overestimate reserves, often yielding mathematically infinite reserves estimates, $\mathrm{b}>1$. To address this problem, different decline curve analysis models have been proposed for tight and shale reservoirs such as Power Law Exponential (PLE), Duong's method and Logistic Growth Analyses (LGA).

The objective of the first part of this study is to find out which of these four decline models reliably forecasts production from hydraulically fractured horizontal shale oil wells. Production data from 100 oil wells from eight counties in the Eagle Ford Shale play of southeast Texas were analyzed as part of this work. Using a regression co-efficient cut-off of $95 \%$, we see that the LGA model fits the production data (both rate and cumulative) from 81 of the 100 wells analyzed. The Arps' hyperbolic and the LGA equation provided the most optimistic/ pessimistic reserves estimates respectively. The second part of this work investigated how the choice of residual function affects the estimate of model parameters and subsequently remaining well life and reserves. For this, the objective was to develop a methodology that maximizes the likelihood of satisfactorily fitting the data with a b-value $<1$ without developing complicated routines. We explored the use of different residual functions and we found out that using logarithmic rate

Corresponding author: Paryani M, College of Engineering and Mines, The Society of Petroleum Engineers, University of Alaska, Fairbanks, USA, Tel: (907) 474-7730; E-mail: mohitparyani.jgd@gmail.com

Received March 03, 2018; Accepted March 26, 2018; Published March 31, 2018

Citation: Paryani M, Ahmadi M, Awoleke O, Hanks C (2018) Decline Curve Analysis: A Comparative Study of Proposed Models Using Improved Residual Functions. J Pet Environ Biotechnol 9: 362. doi: 10.4172/2157-7463.1000362

Copyright: ( 2018 Paryani M, et al. This is an open-access article distributed under the terms of the Creative Commons Attribution License, which permits unrestricted use, distribution, and reproduction in any medium, provided the original author and source are credited. 
residuals maximized this likelihood. We saw that approximately $75 \%$ of the well histories that were fitted using the logarithmic rate residual have hyperbolic b-values $<1$ as opposed to $40 \%$ using the least squares error function-A $87.5 \%$ increase.

\section{Methodology}

\section{Eagle ford shale overview}

The Eagle Ford Shale play is located in the Maverick Basin of Southeast Texas and is approximately 400 miles long and 50 miles wide (Figure 1) [1]. In this study, production data of a hundred oil wells in Eagle Ford Shale play was obtained from Texas Rail Road Commission (TRRC) website. The hundred wells covered eight counties namely, Burleson, Zavala, Gonzales, Karnes, La Salle, Live Oak, Dimmit and De Witt (Figure 1). Some, but not all, of the wells reported the horizontal length and number of fracture stages.

The main objective behind analyzing this data is to check the applicability of the existing decline curve models on Eagle Ford Shale wells. The general procedure is to tune the existing decline models by matching the production rate and/or cumulative data of each well. A model is said to fit 'fairly well' when the regression coefficient between the model output and the actual production date is greater than or equal to $95 \%$. Each tuned model is then used to predict future production rates, remaining reserves and remaining time to reach the abandonment rate of $2 \mathrm{STB} /$ day for each well. The length of production history varies for different wells from 15 to 48 months.

\section{Decline curve analysis and application to eagle ford production data}

Arps' decline curve model: Arps' observed that the ratio of production rate to change in production rate played a crucial role in determining the type of decline a well would undergo. The major underlying assumptions for using Arps' equations are (1) constant bottom hole pressure (2) boundary dominated flow (3) constant drainage area and (4) constant skin factor [2,3].

The exponential form $(b=0)$ typically applies to conventional reservoirs with reasonably high permeability in which a short transient phase is usually followed by boundary dominated flow. However in case of shale reservoirs where matrix permeability is extremely low, it is uncertain and probably unlikely that flow will become boundary dominated during a typical well's producing life.

The hyperbolic form of Arps' work $(0<b<1)$ is typically a concave up curve on a semi log plot of rate versus time. This model is frequently used for conventional reservoirs. However, in cases where boundary dominated flow has been reached, it can also be used for low permeability reservoirs. As stated previously, shale reservoirs have extremely low permeability in the range of nano-darcies. The nano-darcy matrix permeability coupled with the high permeability hydraulic fracture is the cause of long transient flow in shale reservoirs. As such, these wells exhibit high initial rates followed by rapid declines. This and other complexities of shale reservoirs can cause the b-value for Arps' hyperbolic to be greater than 1 [3].

The use of Arps' equation to analyze production data from shale reservoirs is not recommended because these reservoirs sometimes do not attain boundary dominated flow due to their low permeability. Moreover, the drainage area is not constant because the pressure pulse continues to propagate from the near wellbore/fracture to other areas of the stimulated reservoir volume. Under these conditions, the b-value obtained from regression by minimizing the least square error between the values predicted by the Arps's hyperbolic model and the actual production data will be greater than 1 . This in turn leads to erroneous estimates of reserves. However, despite the obvious drawbacks to using Arps' equation in shale reservoirs, it is still a very popular model. We think that the reasons are (1) because it provides a reasonable history match even when $b>1$ and (2) it is a familiar tool.

In any case, because we wanted to compare the impact of different residual functions on the b-value estimates, we used Excel's multivariable solver tool to calculate the parameters from Arps' equation for different error functions. We estimated the decline rate $D_{i}$, initial production rate $q_{i}$, and the decline exponent $b$. This was done by fitting the production data/history using least residual squares. We will discuss the improvements obtained by using different residual functions later in this paper. Once the parameters were obtained, the estimated ultimate recovery (EUR) and the remaining time to reach abandonment were calculated. This was repeated for 100 wells randomly selected from 8 different counties. Figure 2a shows an example history match of Cannon well in Karnes County with the Arps' hyperbolic model. In general, it was observed that Arps' hyperbolic model matched well for all the hundred wells regardless of whether the hyperbolic exponent was normal or abnormal. The significance of abnormal exponent was felt when predicting future performance.

Logistic Growth Analysis (LGA) Model: The LGA model [4,5] is proposed to estimate reserves for reservoirs with extremely low permeability. It was derived from the hyperbolic family of curves and its prediction of cumulative production takes the following formequation (1).

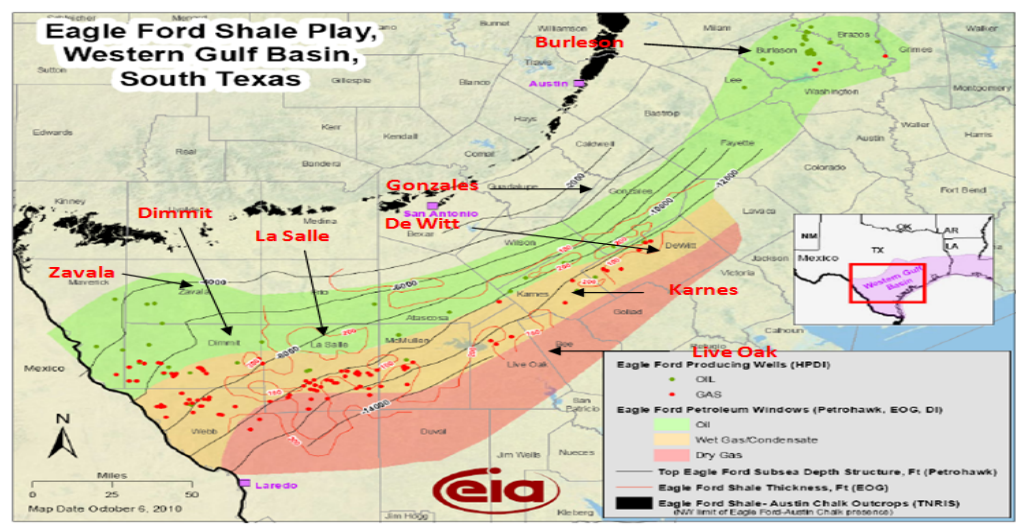

Figure 1: Map of Eagle Ford shale (after Wang and Liu, 2011). 


$$
Q(t)=\frac{K t^{n}}{a^{\prime \prime}+t^{n}}
$$

' $K$ ' is the carrying capacity or the maximum recoverable oil from the reservoir/well. The ' $a$ ' constant is $t^{n}$ at which half of the recoverable oil has been produced. ' $n$ ' is the hyperbolic exponent. By differentiating equation (1), the rate form of the LGA model is obtained and it is stated below-equation (2).

$$
q(t)=n\left(\frac{K}{a}\right)^{\frac{1}{n}} Q(t)^{1-\frac{1}{n}}\left(1-\frac{Q(t)}{K}\right)^{1+\frac{1}{n}}
$$

One of the assumptions is that the parameter ' $K$ ' or the recoverable reserves is already known ahead of time-usually by volumetric calculations. However, ' $K$ ' can also be a fitting parameter. Another assumption is that a single well will be sufficient to drain the entire reservoir over a long period of time. The two major advantages of the LGA model are that (1) the parameter ' $K$ ' ensures the reserves estimate is constrained (this is in contrast to the Arps hyperbolic model) and (2) the production rate is eventually terminated at infinite time which also ensures the reserves estimate is constrained [5].

In our study, the parameters $K, a^{n}$ and $n$ were estimated using Excel's multivariable solver tool. The Logistic Growth Analysis model fitted the hundred wells' past production data very well. For the wells with abnormal hyperbolic exponent, $b>1$, the LGA model constrained the expected ultimate recovery and reported more realistic results compared to the highly optimistic estimates from the hyperbolic model. An example history match from Berry well in Karnes County is shown in Figure $2 \mathrm{~b}$. A very good match for production rate and cumulative production is obtained in this example.

Duong's model: Duong [6] observed that a log-log plot of production rate over cumulative production versus time was always a straight line for unconventional reservoirs. The parameters (slope, $m$ and intercept, a) obtained from this plot are the characteristics of the reservoir rock and fracture stimulation completions. Instead of the traditional Arps' method to evaluate rate and cumulative production based on boundary dominated flow, Duong suggested using the constraints of initial production rate and the production rate at infinity. Duong's work is described primarily by equations (3) and (4).

$$
\begin{aligned}
& \frac{q(t)}{Q(t)}=a t^{-m} \\
& q(t)=q_{1} t(a, m)+q_{\infty} \\
& \text { where, } t(a, m)=t^{-m} \exp \left(\left(\frac{a}{1-m}\right)\left(t^{1-m}-1\right)\right)
\end{aligned}
$$

Typical ranges of these parameters are $1 \leq m \leq 2$ and $0<a \leq 2$. The two major limitations of this model are that when the well is shut in for long periods of time, proper rate initialization according to pressure is required to obtain correct values of parameters ' $a$ ' and ' $m$ '. Secondly, in case of water breakthrough, there is sudden decrease in the decline rate and this causes an increase in values of the ' $a$ ' and ' $m$ ' parameters [6].

In order to analyze Eagle Ford production data using this method, two diagnostic plots were generated using equations (3) and (4): $\log$ $\log$ plot of $q(t) / Q(t)$ versus time and rate versus $t(a, m)$. By plotting the ratio of rate to cumulative production vs. time, the parameters ' $a$ ' and ' $m$ ' were obtained. Thereafter, by plotting rate vs. the time function we get parameters ' $q_{1}$ ' and ' $q_{\alpha}^{\prime}$ '. After obtaining all the model parameters, equations (3) and (4) were algebraically manipulated to provide predictions of rate and cumulative production. Figures $3 \mathrm{a}$ and $3 \mathrm{~b}$ show an example of diagnostic plots for Duong's model. Figure 3a is log-log plot $q(t) / Q(t)$ vs. time. Least square regression trend-line tool in Excel gives the values of parameters ' $a$ ' and ' $m$ '. Figure $3 \mathrm{~b}$ is a diagnostic plot of rate vs. time function which is dependent on parameters ' $a$ ' and
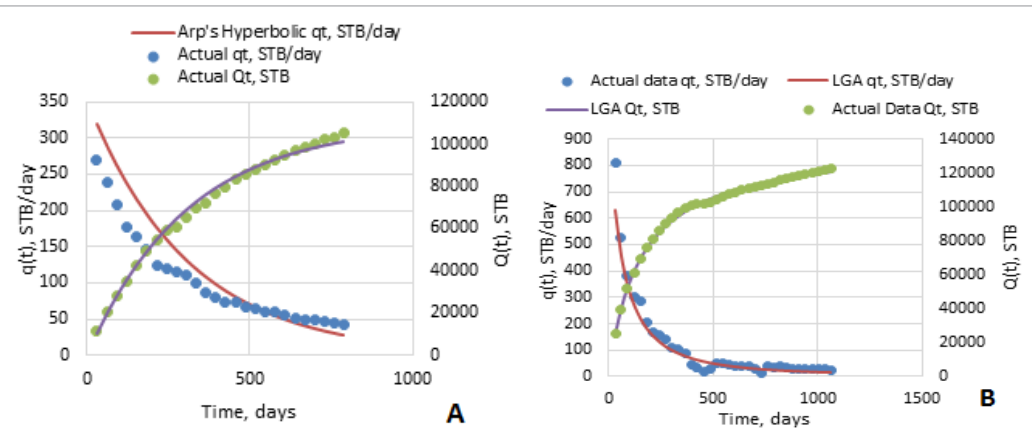

Figure 2: a) Arps' hyperbolic fit for Cannon well (Karnes County) showing rate and cumulative production history match, b) Example of good LGA fit for the Berry well.

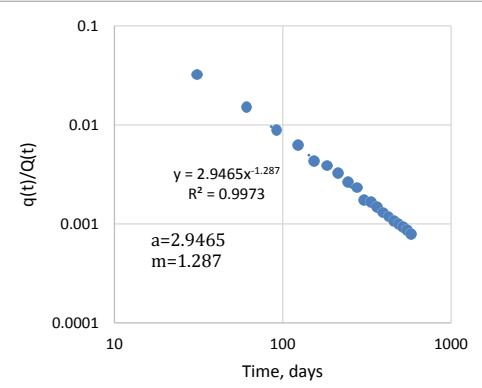

(a)

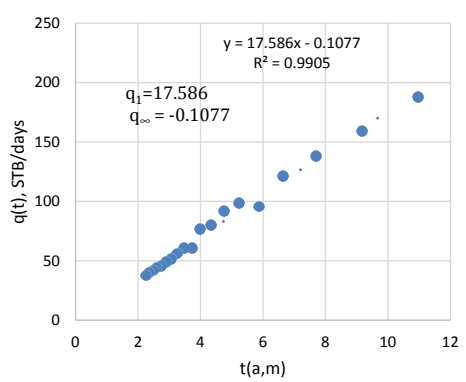

(b)

Figure 3: a) Example determination of a and $m$ parameters for Duong method, b) Example determination of $q_{1}$ and $q_{\infty}$ parameters for Duong method. 
Citation: Paryani M, Ahmadi M, Awoleke O, Hanks C (2018) Decline Curve Analysis: A Comparative Study of Proposed Models Using Improved Residual Functions. J Pet Environ Biotechnol 9: 362. doi: 10.4172/2157-7463.1000362

' $m$ '. The least square regression trend-line gives the values of ' $q_{1}$ ' and ' $q_{\alpha}$ '. Note that when trend-line passes through origin, the value of $q$ becomes zero as it is the intercept of the trend-line (Figure 4a).

Power law exponential (PLE) model: Ilk developed this model [7] and applied to field examples by McNeil [8]. It approximates the rate decline seen in the production from shale gas wells with a power law

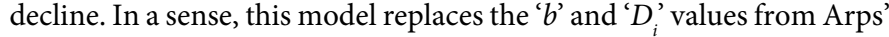
equation with the new parameters ' $D_{1}^{\prime}$, ' $D_{\alpha}$ ' and ' $n$ ' and its rate time takes the following form-equation (7).

$$
\begin{aligned}
& D=D_{\infty}+D_{1} t^{-\left(1-n^{\prime}\right)} \\
& q=\hat{q}_{i} \exp \left(-D_{\infty} t-\left(\frac{D_{1}}{n}\right) t^{n^{\prime}}\right) \\
& q=\hat{q}_{i} \exp \left(-D_{\infty} t-\hat{D}_{i} t^{n^{\prime}}\right)
\end{aligned}
$$

The major advantages of this model are: (1) the extra variables enable the model to account for both transient and boundary dominated flow whenever necessary; and (2) the equation for production rate looks similar to Arps' exponential form which gives the model a familiar feel.

Based on our results, the power law model gives good estimates for reserves even when ample data is not available. The power law model was applied to 100 wells in the Eagle Ford shale play. The least square regression between the PLE rate and actual rate is minimized using Excel's multivariable solver tool. The time to reach abandonment was computed by equating production rate to 2 STB/day. The EUR can be estimated by integrating the rate equation (8) with respect to time,

$$
Q(t)=\int_{0}^{t} \hat{q}_{i} \exp \left(-D_{\infty} t-\hat{D}_{i} t^{n^{\prime}}\right) d t
$$

However, the solution to this integral is not a trivial process. Alternatively, a good approximation for computing the EUR is accomplished numerically by summing up incremental production on a monthly basis until the abandonment rate of $2 \mathrm{STB} /$ day is reached. We can also use the trapezoidal method to solve equation (8). If so, we have the following:

$$
Q(t)=\sum_{i=1}^{x} q(t)_{i} t_{i}
$$

Figure $4 \mathrm{~b}$ shows rate versus time series data for the Muenchow well in Karnes County along with both hyperbolic and power law fits. As seen in the figure, both models fit the production data very well; however, the hyperbolic model fits with a 'b' value of 1.44 which will mathematically cause it to give an unreliable estimate of remaining reserves. The power law fit overcomes this shortcoming as it will terminate at a reasonable time to give more conservative results $[9,10]$.

Summary of DCA models: This above analysis highlights some of the pitfalls associated with using DCA techniques developed for conventional reservoirs in shale well production prediction and reserves estimation with $60 \%$ of the obtained $b$ values being above 1. Using the Arps' hyperbolic equation consistently provided high estimates and may be said to be the optimistic approach for generating future production predictions due to the unusually high Arps' decline exponent. As stated elsewhere in the technical literature, forecasting transient production using an Arps' hyperbolic equation with $b>1$ can lead to a severe overestimation of EUR, and for that matter, remaining reserves.

Overall, the LGA model fits $81 \%$ of the wells' past production rate and cumulative production. The lack of a good history match with the remaining wells may be due to paucity of production history data. The LGA model gives finite EUR estimates when compared to Arps' models.

The Duong's model fits the production rate and cumulative production data for about $51 \%$ wells. The Duong's model performed well when the production history was at least 20-24 months with minimal noise. However, for some cases, even when the data was
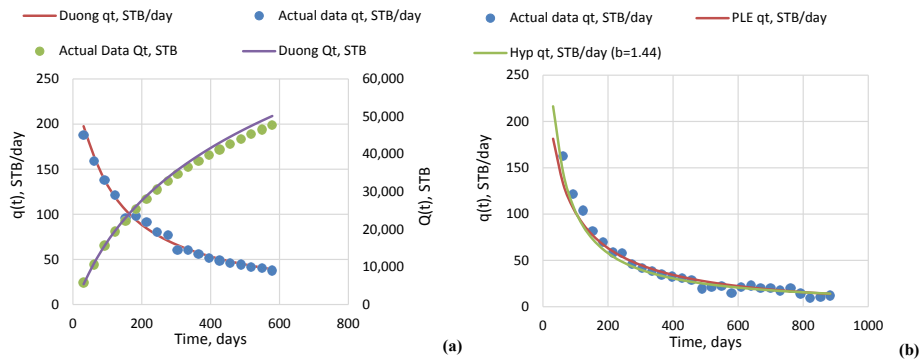

Figure 4: a) Example of Duong's model history match of Berry Well (Karnes County), b) Hyperbolic and PLE fit for Muenchow well in Karnes County.
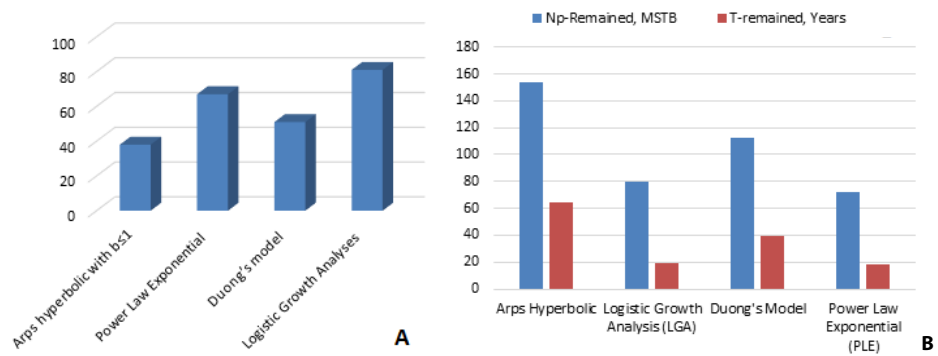

Figure 5: a) Bar chart showing percent fitted based on a regression coefficient of $95 \%$ by investigated models, b) Bar chart comparing performance of investigated models. 
smoothed, Duong's model did not match the production history well. It also occasionally resulted in extremely high reserves estimates like Arps' hyperbolic model or extremely low reserves estimates like Arps' exponential model, with no clear cause.

As PLE comes from exponential family of curves, it is similar to Arps' exponential model. For other cases, the PLE consistently gave the lowest forecasts for all the models. It is therefore the most conservative method for production forecasting and reserves estimation. Based on $\mathrm{R}^{2} \geq 0.95$, PLE fits $67 \%$ of the wells past production rate. The comparison in terms of percentage fitted by each model and remaining reserve/remaining life for each model is shown in Figure 5. As seen in Figure 5a, LGA, which also reports conservative results, remains the most successful technique to model the wells past production performance. Thus it can be inferred that LGA, PLE and the Duong's models do overcome the limitations of Arps' models up to a certain extent when applied to shale reservoirs. However there is still scope of a better model in terms of consistency in fitting the wells past production $[11,12]$.

Using different residual functions to improve forecasting: Numerous efforts have been made to correct the shortcomings associated with using the Arps' equation in unconventional reservoirs. The three models reviewed in the above section overcome the limitations of Arps' models to varying degrees. Clearly, the deterministic models in literature provide a range of estimates indicating the challenges involved in making accurate production forecasts. However, despite all the above, the Arps' model is still widely used for the evaluation of EUR of shale oil/gas wells. This is probably because of its simplicity. Therefore, to improve the applicability of the Arps' model, this study

\begin{tabular}{|c|c|}
\hline Base Error Function & $\sum\left(q_{\text {actual }}-q_{\text {calculated }}\right)^{2}$ \\
\hline Normalized rate & $\sum\left(1-\frac{q_{\text {calculated }}}{q_{\text {actual }}}\right)^{2}$ \\
\hline Inverse Normalized rate & $\sum\left(\frac{1}{q_{\text {actual }}}-\frac{1}{q_{\text {calculated }}}\right)^{2}$ \\
\hline Cumulative & $\sum\left(Q_{\text {actual }}-Q_{\text {calculated }}\right)^{2}$ \\
\hline Normalized cumulative & $\sum\left(1-\frac{Q_{\text {calculated }}}{Q_{\text {actual }}}\right)^{2}$ \\
\hline Logarithmic rate & $\sum A b s\left[\ln \left(\frac{q_{\text {actual }}}{q_{\text {calculated }}}\right)\right]^{2}$ \\
\hline
\end{tabular}

Table 1: Error functions used for analysis. investigates how the choice of residual function affects the estimate of model parameters and subsequently remaining well life and reserves.

In the above study, monthly oil production data is deterministically fitted for each well by constraining the parameters using least residual squares. The residual used for that work is the least square error computed using the fit from the above models and actual rate/ cumulative data. We hereafter call this the base error function. When this error form is used, earlier data points are more heavily weighted. This affects the resulting model parameters and the subsequent forecasts.

To address this problem, two and four different residual functions were defined and are used for the cumulative-time and rate-time forms, respectively (Table 1 ). The objective of the proposed residuals is to weight the most recent production data more heavily. This will ensure that the fitted parameters will reflect the current flow regime in the drainage area of the wells. The LGA and Arps' models were applied to the data using the new residual functions. This process was integrated in an Excel-VBA spreadsheet software $[13,14]$.

\section{Example case study}

Figure 6 shows the various fits using data from Oliver B well in the De Witt County and the different residual functions. Table 2 summarizes the performance of Arps' and LGA models using different error functions with the same data. The base case residual function fits the trend hyperbolically with a b value of 0.76 , whereas the normalized rates, inverse normalized rates and logarithmic residuals fit with $b$ values of $0.41,0.43$, and 0.25 respectively. The cumulative residual function follows harmonic decline with a b value of 1 and normalized cumulative residual fits with a $b$ value 0.91 . Because of the reduction in b-values for both the normalized rates and logarithmic residuals, the predicted remaining life and remaining reserves substantially drops. This results in conservative forecasts comparable with LGA model results.

Figure 7 shows the various fits using data from Haug-Kieschnick Unit 33 in the La Salle County and the different residual functions. Table 3 summarizes the performance of Arps' and LGA models using different error functions with the same data. Base case fits the trend hyperbolically with $\mathrm{b}$ value of 1.49 , whereas the normalized rates, inverse normalized rates and logarithmic residuals fit with $b$ values of $0.67,0.29$, and 0.66 respectively. Again in this case, using these different residual functions leads to lower b-value estimates. This also results in conservative estimates. The cumulative residual follows hyperbolic decline with $\mathrm{a} b$ value of 1.36 and normalized cumulative residual fits with $a b$ value 1.84 . (Note: Since $b>1$ gives unreasonable forecasts, the $b$ value is restricted to 1 for the base case for illustration purposes).

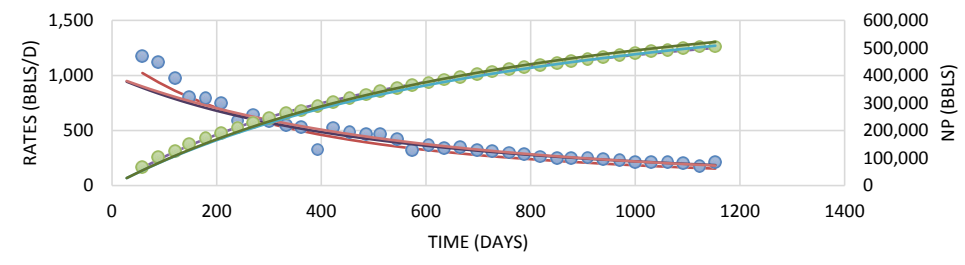


Citation: Paryani M, Ahmadi M, Awoleke O, Hanks C (2018) Decline Curve Analysis: A Comparative Study of Proposed Models Using Improved Residual Functions. J Pet Environ Biotechnol 9: 362. doi: 10.4172/2157-7463.1000362

Page 6 of 8

\begin{tabular}{|c|c|c|c|c|c|}
\hline Model & T-remained, days & Np-Remained, STB & Error Function & Fitting q or $\mathbf{Q}$ vs time & b value \\
\hline Hyperbolic & 47127 & 659763 & Base Case & $q$ & 0.76 \\
\hline Hyperbolic & 12317 & 278718 & Normalized Rate & $q$ & 0.41 \\
\hline Hyperbolic & 13396 & 296967 & Inverse Normalized Rate & $q$ & 0.43 \\
\hline Harmonic & 132227 & 1234697 & Cumulative & Q & 1.00 \\
\hline Hyperbolic & 85402 & 902057 & Normalized Cumulative & Q & 0.91 \\
\hline Hyperbolic & 6910 & 210552 & Logarithmic Rate & $q$ & 0.25 \\
\hline LGA & 21350 & 388802 & Base Case & Q & \\
\hline LGA & 16778 & 299729 & Normalized & $Q$ & \\
\hline
\end{tabular}

Table 2: Results summary for proposed residuals applied to Oliver B well.

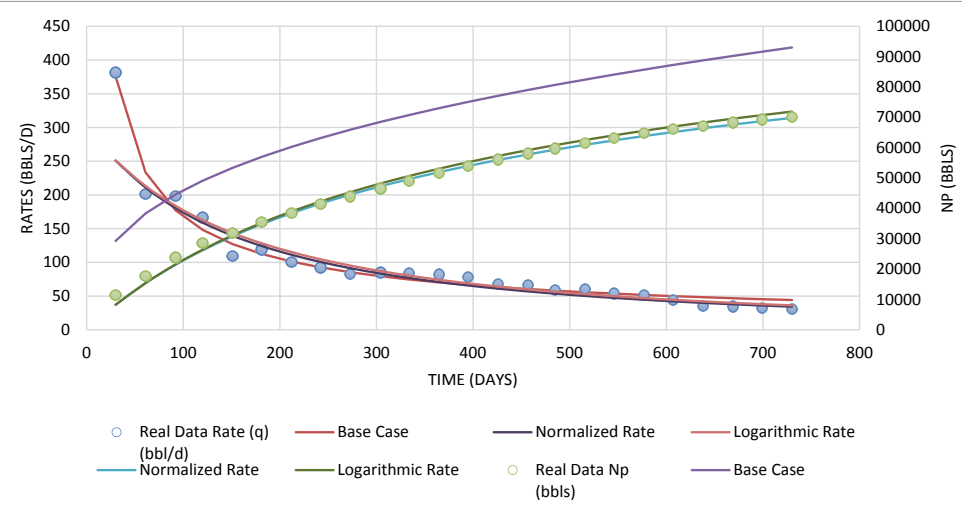

Figure 7: Influence of error function on parameter b for Haug Kieschnick Unit 33 well.

\begin{tabular}{|c|c|c|c|c|c|}
\hline Model & T-remained, days & Np-Remained, STB & Error Function & Fitting q or $\mathbf{Q}$ vs time & b value \\
\hline Harmonic & 12487 & 87236 & Base Case & $q$ & 1.00 \\
\hline Hyperbolic & 5376 & 45767 & Normalized Rate & $q$ & 0.67 \\
\hline Hyperbolic & 1866 & 29434 & Inverse Normalized Rate & $q$ & 0.29 \\
\hline Harmonic & 13417 & 82538 & Cumulative & Q & 1.00 \\
\hline Harmonic & 11500 & 66720 & Normalized Cumulative & Q & 1.00 \\
\hline Hyperbolic & 5554 & 50389 & Logarithmic Rate & q & 0.66 \\
\hline LGA & 5880 & 46613 & Base Case & Q & \\
\hline LGA & 6000 & 44937 & Normalized & Q & \\
\hline
\end{tabular}

Table 3: Results Summary for proposed residuals applied to Haug Kieschnick Unit 33 well.

\section{Statistical analysis of parameters: Residual function analysis}

The box and whisker plots in Figures $8 \mathrm{a}-8 \mathrm{c}$ summarize the center, spread and overall range of the Arps' hyperbolic parameters ' $b$ ', ' $D_{i}$ ' and ' $\mathrm{q}_{\mathrm{i}}$ ' after matching the model to 100 wells in the Eagle Ford shale. Each of the four parts of the boxplots represents $25 \%$ of the data set. The 'Di' boxplots for different error functions are typically skewed towards the bottom implying they usually follow log-normal distributions. The range of data values for normalized rates and logarithmic residuals is narrow as compared to the spread of other cases. Unlike $D_{i}$ values, the 'b' boxplots are typically normal distributed and not skewed. Considering the hyperbolic decline, for the base and cumulative cases, the majority of the values fall above the cut off value of 1 with mean of 1.2 and standard deviation of 0.7. However, the normalized rates and logarithmic residuals limit the b-values to varying degrees.

This observation is strengthened in Figure $8 \mathrm{~d}$ which shows the cumulative distribution functions (CDF) of the $b$ values. The base case CDF shows that approximately $40 \%$ of the b values obtained are below 1. The normalized and logarithmic CDF shows that approximately $60 \%$ and $75 \%$ of the $b$ values obtained using these residuals are below 1 respectively. It is interesting to note that almost $90 \%$ of the b values obtained fall below 1.5 with the normalized-rate and logarithmic-rate error functions.

\section{Influence of residual function on remaining reserve and remaining life}

The statistical analysis of remaining reserves and remaining life to an abandonment rate of 2 bbls/day was done on one hundred oil wells from Eagle Ford Shale County. Figures $9 \mathrm{a}$ and $9 \mathrm{~b}$ show that using the normalized and logarithmic rate-time residual forms increased the tendency of Arps' model to have bounded estimates of reserves. Figures $9 c, 9 d, 9 e$ and $9 f$ show the distributions of remaining reserves obtained from the Arps' using the base case residual fuction, normalized residual fuction, logarithmic residuals and LGA model. All four distributions are log-normally distributed as the high productivity wells do not occur frequently. The Arps' base case forecasts a minimum of 50 MSTB and maximum of 900 MSTB for remaining reserves. The Arps' normalized and Arps' logarithmic residuals forecasts a range of 15-500 MSTB and 50-500 MSTB respectively while the LGA range is 50-450 MSTB for the remaining reserves. This clearly shows that even though the $b$ values are constrained to less than equal to 1 for the base case, the Arps' model will consistently provide optimistic results. On the other hand the newly proposed residuals provide more realistic results similar to that of LGA. 
Citation: Paryani M, Ahmadi M, Awoleke O, Hanks C (2018) Decline Curve Analysis: A Comparative Study of Proposed Models Using Improved Residual Functions. J Pet Environ Biotechnol 9: 362. doi: 10.4172/2157-7463.1000362
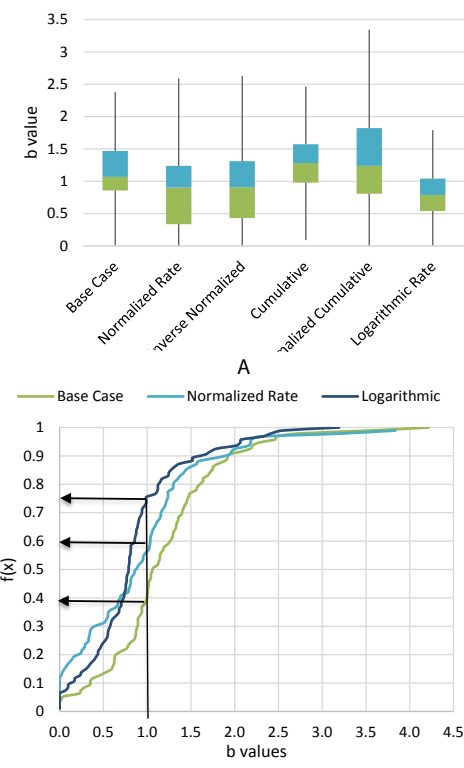

C

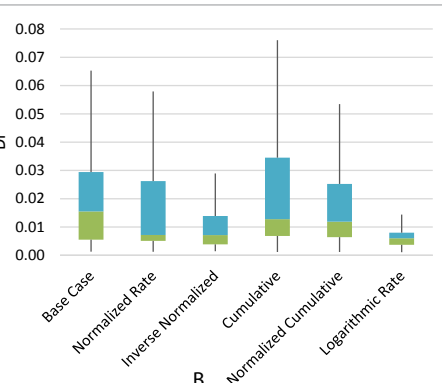

B

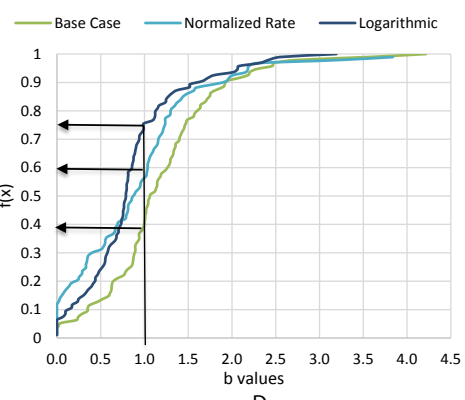

D

Figure 8: a) Box and Whisker plot showing spread of b values for proposed residual functions, $b$ ) Box and Whisker plot showing spread of $D_{i}$ values for proposed residual functions, $c$ ) Box and Whisker plot showing spread of $q_{i}$ values for proposed residual functions, $d$ ) Cumulative distribution function for parameter $b$ for proposed residual functions.

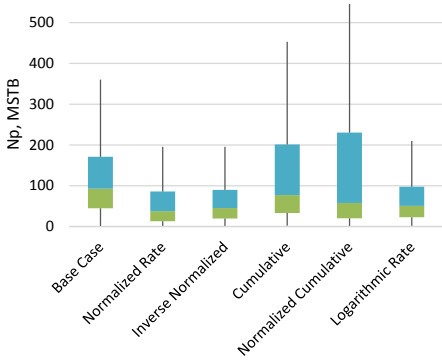

(a)

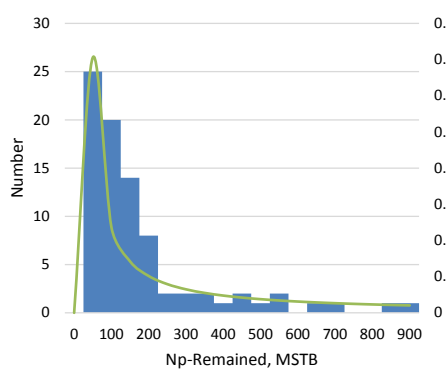

(C)

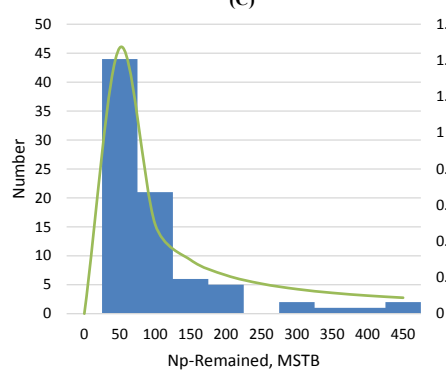

(e)

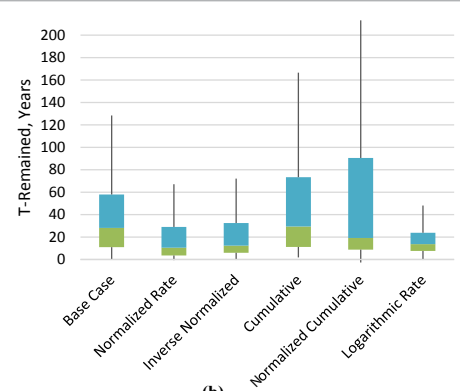

(b)

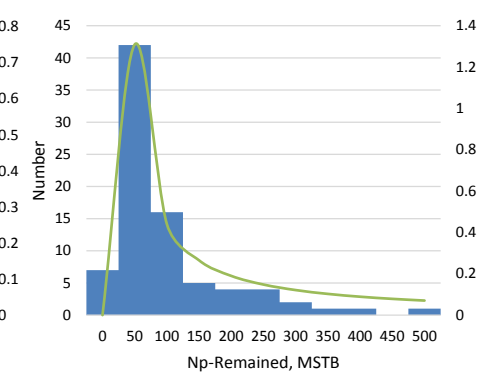

(d)

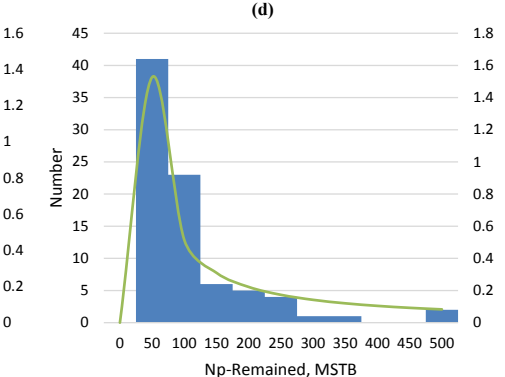

(f)

Figure 9: a) Box and Whisker plot showing spread of remaining reserves for proposed residual functions, b) Box and Whisker plot showing spread of remaining time for proposed residual functions, c) Distribution of remaining reserves with base case in Eagle Ford Shale, d) Distribution of remaining reserves with normalized residual, e) Distribution of remaining reserves with logarithmic residual, f) Distribution of remaining reserves with LGA. 
Citation: Paryani M, Ahmadi M, Awoleke O, Hanks C (2018) Decline Curve Analysis: A Comparative Study of Proposed Models Using Improved Residual Functions. J Pet Environ Biotechnol 9: 362. doi: 10.4172/2157-7463.1000362

Page 8 of 8

\section{Results and Discussion}

Results of this study suggest that applying Arps' hyperbolic model to shale oil wells will consistently provide high, overly optimistic estimates of reserves and long remaining life of shale wells. The LGA, PLE and the Duong's models overcome the limitations of Arps' models to varying degrees. PLE fits the wells' past production rate $67 \%$ of the time. PLE consistently predicted the lowest forecasts of all the models with the most conservative production forecasting and reserves estimation. Duong's model fits the production rate and cumulative production data of about $51 \%$ wells and performed best when longer and less noisy production history was available. However, erratic expected ultimate recover (EUR) prediction indicates that Duong's model needs further improvements.

\section{Conclusion}

The LGA model fits $81 \%$ of the wells' past production rate and cumulative production and gives reasonable EUR estimates as compared to Arps' model. Overall, the LGA model appears to be the most effective at history matching past production and predicting finite reasonable EUR. Even though the normalized cumulative-time residual function gave a good history match, it results in unrealistic values. The Arps' normalized and Arps' logarithmic residual functions reduce the fitting parameters $\mathrm{q}_{\mathrm{i}}, \mathrm{D}_{\mathrm{i}}$ and $\mathrm{b}$ for the Arps' Hyperbolic model by ranges of $15-79 \%, 31-86 \%, 20-35 \%$ respectively. Using the logarithmic and normalized rate-time residuals increases the tendency of Arps' model to have bounded estimates of well's remaining reserves and life by approximately $87.5 \%$ and $50 \%$ respectively. Thus using normalized and logarithmic rate-time residuals overcomes the limitations, and improves the accuracy, of Arps' model in cases of unconventional reservoirs. The proposed residual functions can be used to provide multiple estimations of remaining reserves and/or remaining life using any of the above decline models. They also allow for the most recent production data to be weighted more heavily, thereby ensuring that the fitted parameters reflect the current flow regime in the drainage area of the wells.

\section{References}

1. Chaudhary AS, Ehlig-Economides CA, Wattenbarger RA (2011) Shale oil production performance from a stimulated reservoir volume. Presented at the SPE Annual Technical Conference and Exhibition, Denver, Colorado, USA.

2. Arps JJ (1945) Analysis of decline curves. Transactions of the AIME 160: 228-247.

3. Lee WJ, Sidle R (2010) Gas-reserves estimation in resource plays. SPE Economics \& Management 2: 86-91.

4. Tsoularis A, Wallace $\mathrm{J}$ (2001) Analysis of logistic growth models. Mathematical Biosciences 179: 21-55.

5. Clark AJ, Lake LW, Patzek TW (2011) Production forecasting with logistic growth models. Presented at the SPE Annual Technical Conference and Exhibition, Denver, Colorado, USA

6. Duong AN (2011) Rate-decline analysis for fracture-dominated shale reservoirs SPE Reservoir Evaluation \& Engineering 14: 377-387.

7. Ilk D, Rushing JA, Perego AD, Blasingame TA (2008) Exponential vs. hyperbolic decline in tight gas sands: Understanding the origin and implications for reserve estimates using Arps and Apos; Decline curves. Presented at the SPE Annual Technical Conference and Exhibition, Denver, Colorado, USA.

8. McNeil R, Jeje O, Renaud A (2009) Application of the power law loss-ratio method of decline analysis. Presented at the Canadian International Petroleum Conference, Calgary, Alberta. PETSOC-2009-159.

9. Fetkovich MJ (1980) Decline curve analysis using type curves. SPE Journal of Petroleum Technology 32: 1,065-1,077.

10. Fetkovich MJ, Fetkovich EJ, Fetkovich MD (1996) Useful concepts for decline curve forecasting, Reserve estimation and analysis. SPE Reservoir Engineering 11: 13-22.

11. Kanfar M, Wattenbarger R (2012) Comparison of empirical decline curve methods for shale wells. Presented at the SPE Canadian Unconventional Resources Conference, 30 October-1 November, Calgary, Alberta, Canada.

12. Urbancic T, Baig A (2004) Enhancing recovery in shales through stimulation of pre-existing fracture networks. Presented at the SPE Hydraulic Technology Conference, Woodlands, Texas, USA.

13. Valko PP (2009) Assigning value to stimulation in the Barnett Shale: A simultaneous analysis of 7000 plus production histories and well completion records. Presented at the SPE Hydraulic Fracturing Technology Conference, The Woodlands, Texas, USA. SPE-119369-MS.

14. Wang J, Liu Y (2011) Well performance modeling of eagle ford shale oil reservoirs. Presented at the SPE North American Unconventional Gas Conference and Exhibition, The Woodlands, Texas, USA. SPE-144427-MS. 